\section{EXHIBITION \\ Beauty meets utility at MoMA}

Josie Glausiusz

A pudgy, pink, pig-like creature, lacking a head but sprouting a tuft of unruly hair, sits in a corner of the Museum of Modern Art (MoMA) in New York. Epidermits, a stubbylegged quadruped, was purportedly spawned from a skin-and-hair-cell culture grown from a human cheek swab, and is fed on a 'sustain solution' infused through its tail. If carefully nurtured, it could be expected to live as long as "a large dog or a donated kidney".

So says designer Stuart Karten, who claims that his ten-centimetrelong, yet-to-be-realized organism could be a pet of the future. Our ability to incorporate such fantastic ideas into everyday life is the subject of MoMA's new exhibition, Design and the Elastic Mind, which explores the myriad ways in which our minds rapidly adapt to technological changes. This marvellous hodge-podge of exhibits comprises 200 creations that range in size from nano-scale smiley-faces stitched together from viral DNA, to an imposing five-metre-tall sculpture by Chuck Hoberman called Emergent Surface - a screen of twisting and unfolding slatted steel panels that move in response to changes in light. Practical gadgets sit beside whimsical pieces such as the 'smell augmentation' plugs that artist Susana Soares invites us to stuff up our nostrils.

At their best, these devices marry beauty and utility. Martin and Erik



'Colloidal Alphabet Soup': these 7-micrometre-long polymer letters could be used to label individual cells.

Demaine, a father-and-son team from the Massachusetts Institute of Technology (MIT), created Computational Origami - delicately folded, interlocking paper loops that demonstrate the use of computer-aided design to squeeze large objects into small spaces. A similar concept underlies Robert Lang's origami models of the Fresnel lens for the Eyeglass Space Telescope (a mothballed project of the Lawrence Livermore National Laboratory in California). The lens, if realized, could have been scrunched up, launched and then expanded in space to a diameter of 100 metres - roughly the length of an American football field. Elegance and expediency also underlie the Sonumbra sculpture created by Rachel Wingfield and Mathias Gmachl, a tree-like 'sonic shade of light' that transforms peoples' movements via software into serene sounds that are reminiscent of those produced with a Tibetan singing bowl. Solar cells embedded in the green, umbrellalike shade of Sonumbra harvest energy during the day to power the lights at night.

Some of the most compelling items in Design and the Elastic Mind are simple, yet could prove essential to populations that lack basic equipment. Bernhard Weigl's credit-card-sized 'Lab on a Card' can diagnose an intestinal infection from a small faecal sample in 20 minutes. Emili Padrós's ‘Non-Stop Shoes' use the energy generated from walking and stair-climbing to run lamps and radios. Similarly, the green-keyed XO laptop computer designed by MIT's Media Lab is "lighter than a lunchbox" and has a battery that can be recharged by pulling a cord wrapped like a yo-yo. It is being distributed to schools in Uruguay, Afghanistan, Cambodia and Mexico, among others, as part of the 'One Laptop Per Child' project, a non-profit programme to deliver laptops to the world's poorest children in remote areas.
What makes the exhibition so electrifying is the imagination that drives these innovations. A charming example is a series of drawings inspired by artist Alan Outten, who challenged British primary-school children to design the future. Their inventions included 'Super-Human Mermaid', a genetically engineered human with the genes, gills and tails of a fish "in case the world floods due to pollution", and 'The Apple Phone', a tree with man-made seeds that "use nature as their energy source" to grow apple-like telephones, "so if you are having a private conversation, you just eat the apple". To quote Outten, I left the exhibition "with a sense that creativity and design are safe in the hands of the next generation". Josie Glausiusz is a journalist based in New York.

Design and the Elastic Mind runs at the Museum of Modern Art, New York, until 12 May (www.moma.org).
The second half of Access Denied consists of detailed descriptions of Internet use, regulations and censorship in eight regions of the world, and in each of 40 different countries. The ONI found evidence of censorship in 26 of those 40 . For the other 14 countries, it summarizes the legal and regulatory framework surrounding Internet use, and tests the results that indicated no censorship. This leads to 200 pages of rather dry reading, but it is vitally important to have this information welldocumented and easily accessible. The book's data are from 2006, but the authors promise frequent updates on the ONI website.

No set of Internet censorship measures is perfect. It is often easy to find the same information on uncensored URLs, and relatively easy to get around the filtering mechanisms and to view prohibited web pages if you know what you're doing. But most people don't have the computer skills to bypass controls, and in a country where doing so is punishable by jail - or worse - few take the risk. So even porous and ineffective attempts at censorship can become very effective socially and politically.

In 1996, Barlow said: "You are trying to ward off the virus of liberty by erecting guard posts at the frontiers of cyberspace. These may keep out the contagion for some time, but they will not work in a world that will soon be blanketed in bit-bearing media."

Brave words, but premature. Certainly, there is much more information available to many more people today than there was in
1996. But the Internet is made up of physical computers and connections that exist within national boundaries. Today's Internet still has borders and, increasingly, countries want to control what passes through them. In documenting this control, the ONI has performed an invaluable service.

Bruce Schneier is chief security technology officer for BT Counterpane, Santa Clara, California. He is author of Beyond Fear: Thinking Sensibly About Security in an Uncertain World.

\section{Correction}

Ken Arnold's review of The Anatomist by Bill Hayes (Nature 451, 247; 2008) incorrectly said that the mother's blood enters the fetal heart through a hole. In fact, this hole lets blood move from the right to the left atrium in utero and is sealed after birth. 